\title{
GAMBARAN KADAR HB IBU HAMIL TRIMESTER II DI PUSKESMAS KERTAPATI PALEMBANG TAHUN 2018
}

\author{
Veradilla \\ Program STUDI DIII Kebidanan STIKES Mitra Adiguna Palembang \\ Jln.Kenten Permai Blok J 9-12 Kelurahan Bukit Sangkal Palembang \\ Email : veradilla90@gmail.com
}

\begin{abstract}
Abstrak
Badan kesehatan dunia WorldHealth Organization (WHO) melaporkanbahwa prevalensi ibu-ibu hamil yangmengalami defisiensi besi sekitar 35-75\%,dan kejadian anemia semakin meningkatseiring dengan pertambahan usia kehamilan. Tujuan penelitian ini adalah untuk mengetahui gambaran kadar $\mathrm{Hb}$ ibu hamil trimester II di Puskesmas Kertapati Palembang tahun 2018.Penelitian ini peneliti menggunakan metode deskriptif kuantitatif. Populasi pada penelitian ini adalah semua ibu hamil trimester II yang datang ke Puskesmas Kertapati Palembang pada bulan Maret-Mei tahun 2018 dengan jumlah sampel sebanyak 30 responden. Hasil penelitian didapatkan distribusi frekuensi umur ibu $<20$ tahun sebanyak 2 reponden (6,7\%), umur ibu 20-35 tahun sebesar 22 tahun dan umur ibu > 35 tahun sebesar 6 responden (20\%). Distribusi frekuensi responden yang berpendidikan S1 sebanyak 7 responden (23,3\%), SMU/sederajat sebanyak 16 responden (53,3\%), SMP/sederajat 5 responden (16,7\%) dan SD sebanyak 2 responden (6,7\%). Distribusi frekuensi kadar hemoglobin ibu hamil trimester II sebagian besar normal yaitu sebanyak 23 responden (76,7\%). Saran penelitian ini diharapkan tenaga kesehatan khususnya bidan di Puskesmas Kertapati Palembang lebih meningkatkan dalam pemberian penyuluhan kepada ibu hamil tentang pentingnya mengkonsumsi tablet zat besi untuk mencegah anemia pada kehamilan dengan menggunakan bahasa dan media informasi yang dapat menarik minat ibu hamil dalam mengkonsumsi tablet zat besi seperti menggunakan video atau film dokumenter tentang pemberian tablet zat besi.
\end{abstract}

Kata Kunci

: Tablet Zat Besi, Kadar Hemoglobin

\begin{abstract}
The World Health Organization World Health Organization (WHO) reports that the prevalence of pregnant women with iron deficiency is around 35-75\%, and the incidence of anemia is increasingly increasing with increasing gestational age. The purpose of this study was to determine the description of $\mathrm{Hb}$ levels in second trimester pregnant women in Palembang Kertapati Health Center in 2018. This study used a quantitative descriptive method. The population in this study were all trimester II pregnant women who came to Palembang Kertapati Health Center in March-May 2018 with a total sample of 30 respondents. The results showed that the frequency distribution of mothers aged $<20$ years as many as 2 respondents (6.7\%), the age of mothers 20-35 years at 22 years and maternal age $>35$ years at 6 respondents (20\%). The frequency distribution of respondents with S1 education was 7 respondents (23.3\%), high school / equivalent as many as 16 respondents (53.3\%), junior high school / equivalent 5 respondents (16.7\%) and elementary school as many as 2 respondents (6.7\%) The frequency distribution of hemoglobin levels in second trimester pregnant women was mostly normal, namely 23 respondents (76.7\%). The suggestion of this study is that health workers, especially midwives at the Palembang Kertapati Health Center, should improve the provision of counseling to pregnant women about the importance of consuming iron tablets to prevent anemia in pregnancy by using language and information media that can attract pregnant women to consume iron tablets such video or documentary about giving iron tablets.
\end{abstract}

Keywords: Iron Tablets, Hemoglobin Levels 


\section{PENDAHULUAN}

Ketersediaan sumber daya manusiayang berkualitas yang memiliki kondisifisik, mental, dan sosial yang sehat sertapenguasaan terhadap ilmu dan teknologimerupakan indikator keberhasilanpembangunan suatu bangsa. Upaya untukmeningkatkan kualitas sumber daya manusiaharus dimulai sejak janin dalam kandunganmelalui perbaikan asupan gizi ibu. Asupangizi ibu selama hamil dapat mempengaruhipertumbuhan janin yang sedang dikandung.Ibu yang memiliki asupan gizi yang kurangpada masa hamil kemungkinan besar akanmelahirkan bayi yang tidak sehat, tidakcukup bulan dan terlahir dengan berat badanrendah,kejadian anemia pada ibu hamilmemiliki kontribusi negatif terhadap beratbadanbayi (Hapzahet dalam Ratih, 2017).

Badan kesehatan dunia WorldHealth Organization (WHO) melaporkanbahwa prevalensi ibu-ibu hamil yangmengalami defisiensi besi sekitar 35-75\%,dan kejadian anemia semakin meningkatseiring dengan pertambahan usia kehamilan(Lydiaet dalam Ratih, 2017).

Organisasi kesehatan tingkat dunia,

World Health Organization (WHO) memperkirakan 800 perempuan meninggal setiap harinya akibat komplikasi kehamilan dan proses kelahiran. Sekitar 99\% dari seluruh kematian ibu terjadi di negara berkembang. Sekitar $80 \%$ kematian maternal merupakan akibat meningkatnya komplikasi selama kehamilan, persalinan dan setelah persalinan (WHO dalam Irawan, 2015).

Berdasarkan hasil Riset Kesehatan Dasar (Riskesdas) tahun 2013, angka kejadian anemia di Indonesia masih tinggi, terdapat $37,1 \%$ ibu hamil yang mengalami anemia (Deprika, 2017).

Menurut data dari dinas kesehatan di Provinsi Sumatera Selatan, anemia pada ibu hamil tahun 2012 terdapat $692(1,51 \%)$ orang dari 45.652 ibu hamil, pada tahun 2013 terdapat ibu hamil dengan anemia sebanyak $646(1,77 \%)$ orang dari $36.487 \mathrm{ibu}$ hamil, sedangkan pada tahun 2014 terdapat ibu hamil dengan anemia $675(1,4 \%)$ orang dari 48.235 ibu hamil (Amalia, 2015).

Berdasarkan data Dinas Kesehatan Kota Palembang, jumlah kematian ibu tahun 2015 di Kota Palembang, berdasarkan laporan sebanyak 12 orang dari 29.011 kelahiran hidup (Profil Pelayanan Kesehatan Dasar, 2015).
Penyebabnya yaitu pendarahan $(41.7 \%)$, diikuti oleh emboli paru (1 kasus), suspek syok kardiogenik (1 kasus), eklampsia (1 kasus), suspek TB (1 kasus), hipertensi dalam kehamilan (1 kasus), dan lainnya (Dinkes Kota Palembang, 2016).

Besarnya angka kejadian anemia ibu hamil pada trimester I kehamilan adalah $20 \%$, trimester II sebesar $70 \%$, dan trimester III sebesar $70 \%$.Hal ini disebabkan karena pada trimester pertama kehamilan, zat besi yang dibutuhkan sedikit karena tidak terjadi menstruasi dan pertumbuhan janin masih lambat. Menginjak trimester kedua hingga ketiga, volume darah dalam tubuh wanita akan meningkat sampai $35 \%$, ini ekuivalen dengan $450 \mathrm{mg}$ zat besi untuk memproduksi sel-sel darah merah. Sel darah merah harus mengangkut oksigen lebih banyak untuk janin. Sedangkan saat melahirkan, perlu tambahan besi $300-350$ mg akibat kehilangan darah. Sampai saat melahirkan, wanita hamil butuh zat besi sekitar $40 \mathrm{mg}$ per hari atau dua kali lipat kebutuhan kondisi tidak hamil (Handayani, 2016).

Salah satu dari beberapa faktor tidak langsung penyebab kematian ibu adalah anemia. Pada wanita hamil, anemia meningkatkan frekuensi terjadinya komplikasi pada kehamilan persalinan, resiko kematian maternal, prematuritas, BBLR, dan kematian perinatal. Disamping itu, perdarahan antepartum dan post partum lebih sering dijumpai pada wanita yang anemis dan lebih sering berakibat fatal. Sebab wanita yang anemis tidak dapat mentolerir kehilangan darah (Puspitasari, 2013).

Anemia didefinisikan sebagai keadaan dimana kadar hemoglobin $(\mathrm{Hb})$ dalam darah lebih rendah daripada nilai normal (untuk kelompok orang/anak yang bersangkutan). Anemia gizi besi merupakan masalah gizi mikro terbesar di Indonesia, dimana terjadi pada kelompok balita, anak sekolah, ibu hamil, wanita dan laki-laki dewasa (Proverawati, 2011).

Anemia terjadi pada ibu hamil disebabkan karena kebutuhan ibu terhadap unsur-unsur nutrisi/gizi makanan semakin banyak. Sementara di sisi lain, ibu yang sedang hamil kadang lalai mengkonsumsi zat-zat gizi dalam makanan yang mengaandung zat besi, folid acid, atau pun vitamin B12 (yang umumnya disebabkan ketidaktahuan ibu terhadap unsur-unsur gizi dalam makanan tersebut). Penanggulangan masalah anemia gizi besi saat ini terfokus pada pemberian tablet 
tambah darah (Fe) pada ibu hamil. Ibu hamil mendapat tablet 90 tablet selama kehamilannya. Tapi masih banyak ibu hamil yang menderita anemia hal itu disebabkan karena kurangnya pengetahuan ibu hamil tentang tablet $\mathrm{Fe}$. Sehingga karena kurang pegetahuan dan pemahaman ibu mengenai pentingnya nutrisi dan mengkonsumsi tablet Fe selama kehamilan inilah yang menyebabkan terjadinya anemia pada ibu hamil (Sianipar, 2016).

Pengaruh suplemen besi pada ibuhamil tidak hanya untuk memenuhikebutuhan ibu, tetapi juga dapat membantumemaksimalkan pertumbuhan otak dan beratbadan bayi. Pertambahan berat badan janinmenunjukkan hasil yang lebih rendah padakelompok ibu hamil. Suplemen zat besi padaibu hamil dapat menurunkan sebesar 73\%insiden anemia pada kehamilan aterm dan67\% insiden anemia defisiensi padakehamilan aterm. Hal ini bisa dijelaskanbahwa dengan suplemen zat besi dapatmeningkatkan antara lain retikulosit, seldarah merah,dan hemoglobin (Farid dalam Ratih, 2017).

$$
\text { Kekurangan zat besi juga }
$$

mengakibatkankekurangan hemoglobin $(\mathrm{Hb})$ dimana zat besi sebagaisalah satu unsur pembentukannya. Hemoglobinberfungsi sebagai pengikat oksigen yangsangat di butuhkan untuk metabolisme sel, halini dapat menyebabkan anak lahir dengan beratbadan rendah, keguguran dan juga menyebabkananemia pada bayinya.(Ridwanamiddin dalam Astuti, 2015).

Pengetahuan adalah mencakup apa yang diketahui oleh seseorang terkait dengan sehat dan sakit atau cara-cara memelihara kesehatan. Pengetahuan ibu hamil tentang anemia, makanan sumber zat besi serta perlunya minum tablet $\mathrm{Fe}$ relatif rendah.Untuk mengantisipasi faktor yang mendasari timbulnya masalah pengetahuan, sikap dan perilaku pada ibu hamil, maka pemberian informasi dan edukasi merupakan kegiatan yang harusdilakukan untuk menanggulangi anemia pada ibu hamil (Notoatmojo dalam Triyani, 2016).

Berdasarkan data Puskesmas Kertapati Palembang, jumlah ibu hamil tahun 2015 sebanyak 894 orang, tahun 2016 sebanyak 900 orang dan tahun 2017 sebanyak 875 orang sedangkan tahun 2018 terhitung 1 Januari hingga 31 Mei 2018 sebanyak 284 orang.

Dari hasil studi pendahuluan di Puskesmas Kertapati Palembang yang dilakukan dengan wawancara singkat kepada 7 orang ibu hamil didapatkan 5 orang ibu hamil yang tidak patuh dalam mengkonsumsi tablet $\mathrm{Fe}$, dengan alasan setelah meminum tablet $\mathrm{Fe}$ timbul mual muntah, feseskeras dan berwarna kehitaman, pusing dan juga kepercayaan diri pasien yang menyatakan bahwa kehamilannya sehat dan tidak perlu tambahan suplement.

Berdasarkan latar belakang diatas, peneliti tertarik untuk melakukan penelitian dengan judul "Gambaran Kadar Hb Ibu Hamil Trimester II Di Puskesmas Kertapati Palembang Tahun 2018".

\section{METODE PENELITIAN}

\section{Ruang Lingkup Penelitian}

Penelitian dilakukan pada semua ibu hamil trimester II yang datang ke Puskesmas Kertapati Palembang pada saat penelitian dengan tujuan untuk mengetahui pengaruh pemberian tablet zat besi terhadap peningkatan kadar hemoglobin pada ibu hamil trimester II di Puskesmas Kertapati Palembang tahun 2018.

\section{Rancangan Penelitian}

Penelitian ini peneliti menggunakan metode deskriptif kuantitatif dengan pendekatan cross sectional menggunakan data primer yang diperoleh melalui wawancara dan menggunakan daftar pertanyaan berupa hasil observasi untuk mengukur kadar $\mathrm{Hb}$ ibu hamil trimester II Di Puskesmas Kertapati Palembang

\section{Waktu Penelitian}

Penelitian ini dilaksanakan pada tanggal 4 April - 10 Juni 2018.

\section{Tempat Penelitian}

Penelitian ini di lakukan diPuskesmas Kertapati Palembang.

\section{Populasi dan Sampel Populasi}

Populasi pada penelitian ini adalah semua ibu hamil trimester II yang datang ke Puskesmas Kertapati Palembang pada bulan Maret-Mei tahun 2018.

Sampel

Sampel dalam penelitian adalah sebagian ibu hamil trimester II yang datang ke Puskesmas Kertapati Palembang pada bulan Maret-Mei tahun 2018.

\section{Teknik Pengambilan Sampel}

Pengambilan sampel pada penelitian ini dilakukan dengan cara non probability sampling dengan metode accidental sampling yaitu 
penentuan sampel dengan cara mendapatkan secara kebetulan pada saat peneliti mengadakan penelitian atau ada di lapangan. (Notoatmodjo, 2012).

\section{Jenis Data}

\section{Data Primer}

Dalam penelitian ini data primer didapatdengan melakukan pemberian tablet zat besi pada ibu hamil trimester II yang datang ke Puskesmas Kertapati Palembang serta melakukan pemeriksaan kadar hemoglobin ibu. Kemudian pada kunjungan berikutnya akan dilakukan pemeriksaan kadar hemoglobin kembali untuk mengetahui kadar hemoglobin ibu setelah pemberian tablet zat besi.

\section{Data Sekunder}

Dalam penelitian ini data sekunder didapat dari data Puskesmas Kertapati Palembang, buku sumber, jurnal dan bahan dari internet yang berhubungan dengan topik penelitian.

\section{Teknik Analisis Data \\ Analisa Univariat}

Analisa univariat dilakukan untuk mengukur distribusi frekuensi kadar $\mathrm{Hb}$ ibu hamil trimester II.

\section{HASIL PENELITIAN DAN PEMBAHASAN}

\section{Hasil Penelitian}

\section{Karakteristik Informan}

\section{Umur Ibu}

\begin{tabular}{cccc} 
& \multicolumn{2}{c}{ Tabel 4.1 } \\
& $\begin{array}{c}\text { Distribusi Frekuensi } \\
\text { Di Puskesmas Kertapati Palembang Tahun } 2018\end{array}$ \\
& & & \\
\hline No & Umur Ibu & Jumlah & Persentase (\%) \\
\hline 1. & $<20$ tahun & 2 & 6,7 \\
2. & $20-35$ tahun & 22 & 73,3 \\
3. & $>35$ tahun & 6 & 20 \\
\hline & Jumlah & 30 & 100 \\
\hline
\end{tabular}

Berdasarkan tabel 4.1 diketahui distribusi frekuensi umur ibu $<20$ tahun sebanyak 2 reponden $(6,7 \%)$, umur ibu 20-35 tahun sebesar 22 tahun dan umur ibu > 35 tahun sebesar 6 responden $(20 \%)$.

\section{Pendidikan Ibu}

\begin{tabular}{|c|c|c|c|}
\hline \multicolumn{4}{|c|}{$\begin{array}{c}\text { Tabel } 4.2 \\
\text { Distribusi Frekuensi } \\
\text { Trerdasrkan Pendidikan Ibu Hamil } \\
\text { Trimester II Di Puskesmas Kertapati Palembang } \\
\text { Tahun } 2018\end{array}$} \\
\hline No & Pendidikan Ibu & Jumlah & Persentase (\%) \\
\hline 1. & $\mathrm{~S} 1$ & 7 & 23,3 \\
\hline 2. & SMU/sederajat & 16 & 53,3 \\
\hline 3. & SMP/sederajat & 5 & 16,7 \\
\hline 4. & $\mathrm{SD}$ & 2 & 6,7 \\
\hline 5. & Tidak tamat SD & 0 & 0 \\
\hline & Jumlah & 30 & 100 \\
\hline
\end{tabular}

Berdasarkan tabel 4.2 diketahui distribusi frekuensi responden yang berpendidikan $\mathrm{S} 1$ sebanyak 7 responden $(23,3 \%)$, SMU/sederajat sebanyak 16 responden $(53,3 \%)$, SMP/sederajat 5 responden $(16,7 \%)$ dan SD sebanyak 2 responden $(6,7 \%)$.

\section{Analisis Univariat}

\section{Kadar Hemoglobin Ibu Hamil Trimester II}

Penelitian ini dilakukan pada 30 responden dimana kadar hemoglobin ibu hamil trimester II dikelompokkan menjadi 2 kategori yaitunormal (Jika kadar hemoglobin ibu $\geq 10 \mathrm{~g} / \mathrm{dl}$ ), dan anemia (Jika kadar hemoglobin ibu $<10 \mathrm{~g} / \mathrm{dl}$ ). Adapun tabel distribusi frekuensi kadar hemoglobin ibu hamil trimester II adalah sebagai berikut:

\begin{tabular}{|c|c|c|c|}
\hline \multicolumn{4}{|c|}{$\begin{array}{c}\text { Tabel } 4.3 \\
\text { Distribusi Frekuensi Kadar Hemoglobin Ibu Hamil Trimester II } \\
\text { Di Puskesmas Kertapati Palembang Tahun } 2018\end{array}$} \\
\hline No & $\begin{array}{c}\text { Kadar Hemoglobin } \\
\text { Ibu Hamil } \\
\text { Trimester II } \\
\end{array}$ & Jumlah & $\begin{array}{l}\text { Persentase } \\
\quad(\%)\end{array}$ \\
\hline 1. & Normal & 23 & 76,7 \\
\hline 2. & Anemia & 7 & 23,3 \\
\hline & Jumlah & 30 & 100 \\
\hline
\end{tabular}

Berdasarkan tabel 4.2 diketahui distribusi frekuensi kadar hemoglobin ibu hamil trimester II sebagian besar normal yaitu sebanyak 23 responden $(76,7 \%)$ dan ibu hamil yang mengalami anemia sebanyak 7 responden $(23,3 \%)$.

\section{Pembahasan}

\section{Karakteristik Berdasarkan Usia Ibu}

Berdasarkan tabel 4.2 diketahui distribusi frekuensi umur ibu $<20$ tahun sebanyak 2 reponden $(6,7 \%)$, umur ibu 20-35 tahun sebesar 22 tahun dan umur ibu $>35$ tahun sebesar 6 responden $(20 \%)$. 
Menurut Unicef paritas atau jumlah anak yang dilahirkan ibu sangat berkaitan dengan jarak kelahiran. Semakin tinggi paritasnya, maka semakin pendek jarak kelahirannya. Hal ini dapat membuat seorang ibu belum cukup waktu untuk memulihkan kondisi tubuhnya. Paritas yang tinggi dapat menyebabkan kondisi kesehatan ibu menurun dan sering mengalami kurang darah sehingga berpengaruh buruk pada kehamilan selanjutnya (Purwandari, 2016).

Umur ibu hamil dengan kejadian Anemia - Dalam reproduksi sehat dikenal bahwa usia kehamilan yang aman untuk kehamilan dan persalinan adalah 21-35 tahun. Kehamilan pada usia muda lebih beresiko dibandingkan dengan usia dalam reproduksi sehat, angka kesakitan dan angka kematian ibu dan bayi pada kehamilan remaja dua hingga empat kali lebih tinggi dibandingkan dengan kehamilan di usia 20-35 tahun. Pada penelitian yang dilakukan di Southeast Ethiopia prevalensi Anemia lebih tinggi $(34,6 \%)$ pada wanita hamil dalam kelompok usia 18- 26 tahun hal ini membuktikan bahwa usia juga dapat menjadi faktor resiko (Rizkah, 2016).

Kehamilan pada usia muda dapat menyebabkan terjadiya kompetisi makanan antar janin dan ibunya yang masih dalam pertumbuhan dan adanya pertumbuhan hormonal yang terjadi selama kehamilan. Sedangkan ibu hamil diatas 35 tahun cenderung mengalami Anemia, hal ini disebabkan adanya pengaruh turunnya cadangan zat besi dalam tubuh akibat masa fertilisasi (Rizkah, 2016).

\section{Karakteristik Berdasarkan Pendidikan Ibu}

Berdasarkan tabel 4.3 diketahui distribusi frekuensi responden yang berpendidikan S1 sebanyak 7 responden $(23,3 \%)$, SMU/sederajat sebanyak 16 responden $(53,3 \%)$, SMP/sederajat 5 responden $(16,7 \%)$ dan SD sebanyak 2 responden $(6,7 \%)$.

Tingkat pendidikan sangat mempengaruhi bagaimanan seseorang untuk bertindak dan mencari penyebab serta solusi dalam hidupnya. Orang yang berpendidikan tinggi biasanya akan bertindak lebih rasional. Oleh karena itu orang yang berpendidikan akan lebih mudah menerima gagasan baru. Demikian halnya dengan ibu yang berpendidikan tinggi akan memeriksakan kehamilannya secara teratur demi menjaga keadaan kesehatan dirinya dan anak dalam kandungannya.(Walyani dalam Mariza, 2015).
Pendidikan secara umum adalah segala upaya yang direncanakan untuk mempengaruhi orang lain baik individu, kelompok masyarakat sehingga mereka melakukan apa yang diharapkan oleh pelaku pendidikan. Tingkat rendahnya pendidikan eret kaitannya dengan tingkat pengertian tentang zat bezi $(\mathrm{Fe})$ serta kesadarannya terhadap konsumsi tablet $(\mathrm{Fe})$ untuk ibu hamil. Keadaan defisiensi besi ibu hamil sangat ditentukan oleh banyak faktor antara lain tingkat pendidikan ibu hamil. Tingkat pendidikan ibu hamil yang rendah akan mempengaruhi penerimaan informasi sehingga pengetahuan tentenga zat besi $(\mathrm{Fe})$ menjadi terbatas dan berdampak pada terjadinya defisiensi besi.(Elisabeth dalam Mariza, 2015).

Pendidikan sangat mempengaruhi kemampuan seseorang dalam informasi gizi. Semakin tinggi tingakat pendidikan (lama sekolah) seseorang, semakin mudah menerima hidup sehat secara mandiri, kreaktif dan berkesinambungan. Oleh karena itu tingkat pendidikan mempunyai hubungan yang eksponensial terhadap status gizi dan kesehatan. Makin tinggi pendidikan makin tinggi pula kesadaran ibu untuk mendapatkan gizi yang baik sehingga tidak menimbulkan anemia pada kehamilan. Ibu hamil anemia dengan pendidikan rendah prevalensinya lebih besar daripada ibu yang berpendidikan tinggi. Pendidikan erat dengan kemampuan menerima informasi yang berkaitan dengan kesehatan terutama pada ibu hamil anemia, seperti pengetahuan anemia, pemilihan makanan tinggi zat besi dan asupan zat besi (Mariza, 2015).

\section{Kadar Hemoglobin Ibu Hamil Trimester II}

Berdasarkan analisis univariat diketahui bahwa distribusi frekuensi kadar hemoglobin ibu hamil trimester II sebagian besar normal yaitu sebanyak 23 responden $(76,7 \%)$ dan ibu hamil yang mengalami anemia sebanyak 7 responden $(23,3 \%)$.

Hasil penelitian ini sejalan dengan hasil penelitian yang dilakukan Sulastijah (2015) yang berjudul pengaruh pendidikan gizi dalam upaya meningkatkan kepatuhan konsumsi zat besi melalui kelas ibu hamil di Kecamatan Gatak Sukoharjo. Hasil penelitian didapatkan rerata skor tingkat pengetahuan awal responden kelompok perlakuan adalah 75,15 dan skor tingkat pengetahuan akhir responden adalah $87,87$.

Hasil penelitian ini juga sejalan dengan penelitian Adawiyani (2013) yang berjudul 
pengaruh pemberian booklet anemia terhadap pengetahuan, kepatuhan minum tablet tambah darah dan kadar hemoglobin ibu hamil di Poli Hamil Rumah Sakit Angkatan Laut (Rumkital) Dr.Ramelan Surabaya. Hal ini menunjukkan bahwa metode edukasi berupa pemberian booklet anemia dapat memberi peningkatan pengetahuan pada ibu hamil. Pengukuran kadar $\mathrm{Hb}$ awal ibu hamil pada kelompok uji menunjukkan bahwa sebanyak $8 \%$ ibu hamil yang mengalami anemia dan $92 \%$ yang tidak mengalami anemia. Kemudian pada pengukuran kadar $\mathrm{Hb}$ akhir menggambarkan bahwa sebanyak $100 \%$ ibu hamil tidak mengalami anemia.

Hal ini sesuai dengan pernyataan Farid dalam Ratih (2017), yang menyatakan bahwa pengaruh suplemen besi pada ibu hamil tidak hanya untuk memenuhi kebutuhan ibu, tetapi juga dapat membantu memaksimalkan pertumbuhan otak dan berat badan bayi. Pertambahan berat badan janin menunjukkan hasil yang lebih rendah pada kelompok ibu hamil. Suplemen zat besi pada ibu hamil dapat menurunkan sebesar 73\% insiden anemia pada kehamilan aterm dan $67 \%$ insiden anemia defisiensi pada kehamilan aterm. Hal ini bisa dijelaskan bahwa dengan suplemen zat besi dapat meningkatkan antara lain retikulosit, sel darah merah,dan hemoglobin.

Hal serupa dinyatakan Sianipar (2016), yang menyatakan bahwa anemia terjadi pada ibu hamil disebabkan karena kebutuhan ibu terhadap unsur-unsur nutrisi/gizi makanan semakin banyak. Sementara di sisi lain, ibu yang sedang hamil kadang lalai mengkonsumsi zat-zat gizi dalam makanan yang mengaandung zat besi, folid acid, atau pun vitamin B12 (yang umumnya disebabkan ketidaktahuan ibu terhadap unsur-unsur gizi dalam makanan tersebut). Penanggulangan masalah anemia gizi besi saat ini terfokus pada pemberian tablet tambah darah $(\mathrm{Fe})$ pada ibu hamil. Ibu hamil mendapat tablet 90 tablet selama kehamilannya. Tapi masih banyak ibu hamil yang menderita anemia hal itu disebabkan karena kurangnya pengetahuan ibu hamil tentang tablet $\mathrm{Fe}$. Sehingga karena kurang pegetahuan dan pemahaman ibu mengenai pentingnya nutrisi dan mengkonsumsi tablet Fe selama kehamilan inilah yang menyebabkan terjadinya anemia pada ibu hamil.

Pernyataan serupa dinyatakan Susiloningtyas (2015), menyatakan bahwa masukan zat besi setiap hari diperlukan untuk mengganti zat besi yang hilang melalui tinja, air kencing dan kulit. Kehilangan basal ini kira-kira $14 \mathrm{ug}$ per $\mathrm{Kg}$ berat badan per hari atau hampir sarna dengan $0,9 \mathrm{mg}$ zat besi pada laki-laki dewasa dan $0,8 \mathrm{mg}$ bagi wanita dewasa. Kebutuhan zat besi pada ibu hamil berbeda pada setiap umur kehamilannya, pada trimester I naik dari $0,8 \mathrm{mg} /$ hari, menjadi $6,3 \mathrm{mg} / \mathrm{hari}$ pada trimester III. Kebutuhan akan zat besi sangat menyolok kenaikannya. Dengan demikian kebutuhan zat besi pada trimester II dan III tidak dapat dipenuhi dari makanan saja, walaupun makanan yang dimakan cukup baik kualitasnya dan bioavailabilitas zat besi tinggi, namun zat besi juga harus disuplai dari sumber lain agar supaya cukup.

Hal ini sesuai dengan teori Safrudin (2011), yang menjelaskan bahwa untuk mencegah anemia pada ibu hamil sebaiknya diberi tablet zat besi agar menjamin tercukupinya kebutuhan zat besi untuk janin, terutama perkembangan otak dan darah. Pada trimester pertama kehamilan, zat besi yang dibutuhkan sedikit karena tidak terjadi menstruasi dan pertumbuhan janin masih lambat. Menginjak trimester kedua hingga ketiga, volume darah dalam tubuh wanita akan meningkat sampai $35 \%$, ini ekuivalen dengan $450 \mathrm{mg}$ zat besi untuk memproduksi sel-sel darah merah. Sel darah merah harus mengangkut oksigen lebih banyak untuk janin. Sedangkan saat melahirkan, perlu tambahan besi 300-350 mg akibat kehilangan darah. Sampai saat melahirkan, wanita hamil membutuhkan zat besi sekitar $40 \mathrm{mg}$ perhari atau dua kali lipat kebutuhan kondisi tidak hamil.

\section{KESIMPULAN DAN SARAN}

\section{Kesimpulan}

Berdasarkan hasil penelitian yang telah dilakukan di Puskesmas Kertapati Palembang, dapat disimpulkan bahwa:

1. Distribusi frekuensi umur ibu $<20$ tahun sebanyak 2 reponden $(6,7 \%)$, umur ibu 20 35 tahun sebesar 22 tahun dan umur ibu > 35 tahun sebesar 6 responden (20\%).

2. Distribusi frekuensi responden yang berpendidikan S1 sebanyak 7 responden (23,3\%), SMU/sederajat sebanyak 16 responden $(53,3 \%), \quad \mathrm{SMP} /$ sederajat 5 responden $(16,7 \%)$ dan SD sebanyak 2 responden $(6,7 \%)$. 
3. Distribusi frekuensi kadar hemoglobin ibu hamil trimester II sebagian besar normal yaitu sebanyak 23 responden $(76,7 \%)$ dan ibu hamil yang mengalami anemia sebanyak 7 responden $(23,3 \%)$.

\section{Saran}

Diharapkan tenaga kesehatan khususnya bidan di Puskesmas Kertapati Palembang lebih meningkatkan dalam pemberian penyuluhan kepada ibu hamil tentang pentingnya mengkonsumsi tablet zat besi untuk mencegah anemia pada kehamilan dengan menggunakan bahasa dan media informasi yang dapat menarik minat ibu hamil dalam mengkonsumsi tablet zat besi seperti menggunakan video atau film dokumenter tentang pemberian tablet zat besi.

\section{DAFTAR PUSTAKA}

Astuti, Esthi Widi. 2015. Pengaruh Pendidikan Kesehatan Terhadap Perubahan Pengetahuan Dan Sikap Ibu Hamil Dalam Mengkonsumsi Tablet Fe (Ferum) Di Rumah Bersalin Sri Lumintu Surakarta. Jurnal Fakultas Ilmu Kesehatan Universitas Muhammadyah Palembang.

Dahlan, Sopiyudin. 2012. Statistik untuk kedokteran dan kesehatan: Deskriptif, Bivariat, dan Multivariat. Jakarta : Sagung Seto.

Departemen Gizi dan Kesmas. 2007. Gizi dan kesehatan masyarakat. Jakarta: Fakultas Kesehatan Masyarakat Universitas Indonesia

Dinkes Kota Palembang. 2016. Angka kematian ibu di Kota Palembang tahun 2015

Dinkes Provinsi Sumatera Selatan. 2016. Angka Kematian Ibu Di Provinsi Sumatera Selatan Tahun 2015

Irianto, Koes. 2014. Gizi seimbang dalam kesehatan reproduksi. Bandung : Alfabeta

Maryam, Siti. 2016. Gizi dalam kesehatan reproduksi. Jakarta : Salemba Medika

Notoatmodjo, Soekidjo. 2012. Metode penelitian kesehatan. Jakarta : Rineka Cipta.

Proverawati, Atikah. 2011. Buku ajar gizi untuk kebidanan. Yogyakarta: Nuhamedika
Puspitasari. 2013. Pengaruh penyuluhan terhadap pengetahuan ibu hamil trimester I tentang tablet Fe. Jurnal Kebidanan Universitas Muhammadiyah Semarang.

Ratih, Rini Hariani. 2017. Pengaruh pemberian zat besi $(\mathrm{Fe})$ terhadap peningkatan Hemoglobin Ibu Hamil Anemia. Jurnal Vol 1. No.2, Juli 2017

Sianipar, Siti Santy. 2016. Pengaruh pendidikan kesehatan tentang anemia pada kehamilan terhadap pengetahuan ibu hamil di UPT Puskesmas Bukit Hindu Palangka Raya. Jurnal Kesehatan Vo.7 No.1 tahun 2017

Sulastijah. 2015. Pengaruh Pendidikan Gizi Dalam Upaya Meningkatkan Kepatuhan Konsumsi Zat Besi Melalui Kelas Ibu Hamil Di Kecamatan Gatak Sukoharjo.

Susiloningtyas, Is. 2015. Pemberian zat besi ( $\mathrm{Fe}$ ) dalam kehamilan.Jurnal D.III Kebidanan Fakultas Ilmu Keperawatan Universitas Islam Sultan Agung Semarang

Syafrudin, Karningsih dan Mardiana. 2011. Untaian materi penyuluhan KIA (Kesehatan ibu dan anak). Jakarta : TIM

Triyani, Sugeng. 2016. Kepatuhan Konsumsi Tablet Fe Dalam Mencegah Anemi Gizi Besi Pada Ibu Hamil Di Wilayah Puskesmas Kecamatan Jakarta Pusat. Jurnal Vol. 3 No. 2, Maret 2016, hal : 215-229

Walyani, Elisabeth Siwi. 2015. Asuhan kebidanan pada kehamilan. Yogyakarta : Pustaka Baru Press. 